\title{
Efficacy of a peer interactive youth-led drug prevention programme: a UYDEL-UNODC project
}

Rogers Kasirye.

Uganda Youth Development Link, Kampala, Uganda.

Correspondence email: kasiryer@yahoo.com

\begin{abstract}
While most substance abuse programmes rely more on non-interactive delivery interventions to help the youth, youth-led involvement in substance abuse prevention has been found to be more effective. The delivery of the non-interactive programmes contains several weaknesses, such as passivity of youth participants. Teachers sometimes may be unaccountable in passing over information or may assume the youth already know. Youth-led interactive programmes have a high rate of authority and significantly register less drunkenness and lower alcohol use among peer-led groups. In screening and selecting, peers look or those who are helpful, trustworthy, concerned and those who are good listeners. A key conclusion is that these programmes need to be supported, monitored and sometimes supplemented by other intervention models so as not to under-rate or over-emphasise and assume that "one size fits all".
\end{abstract}




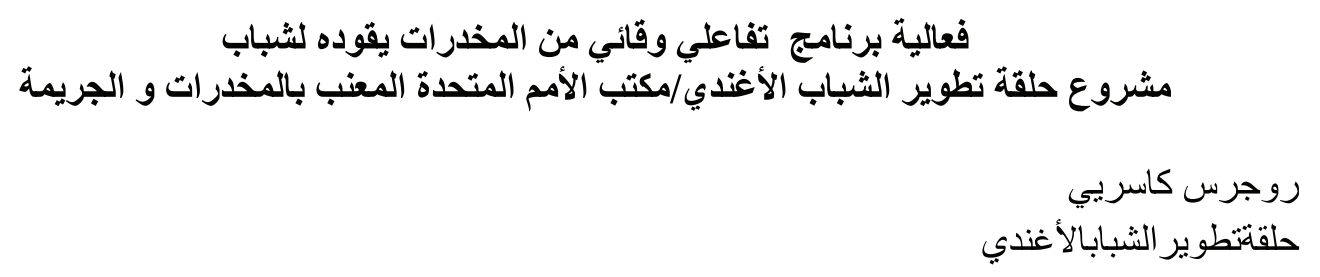

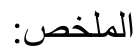

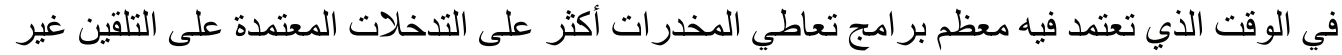

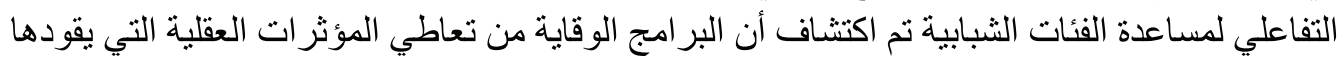

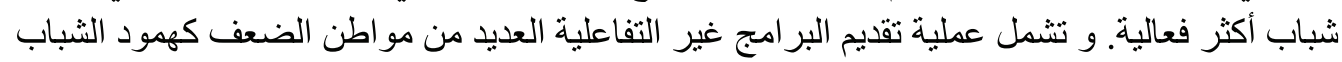
المشاركين خلال عملية تقديم هذه البرنامج و في بعض الحالات هناك درجة من اللامسؤولية في من لدن الدئ

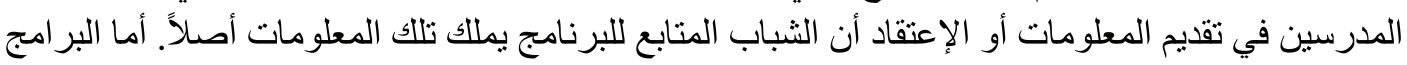

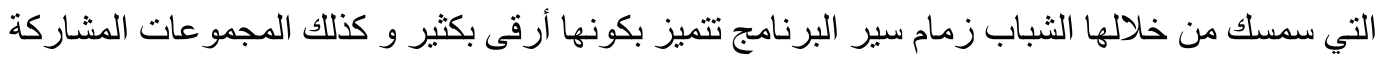
فيها لها نسب سكر و تعاطي كحول أقل بكثير من مجمو عات البر امج الأخرى. و يسعى الثباب في محاولة

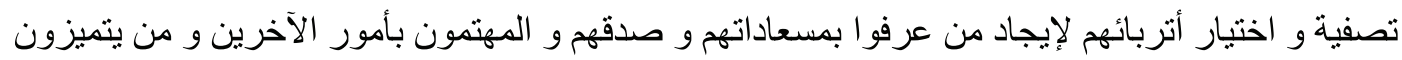
بقدرتهم على الإستماع للآخرين.

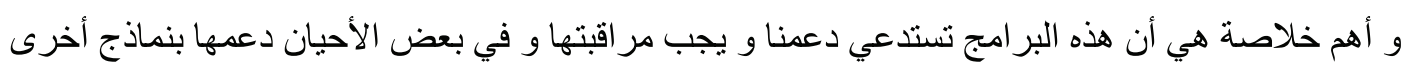

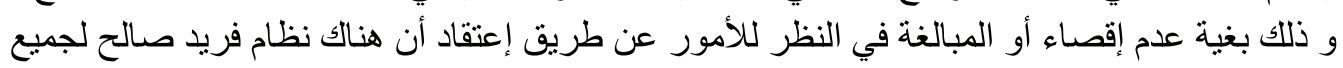

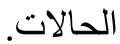

Keywords: Youth-led interactive programmes, Peer-led groups

\section{Introduction}

According to the problem behaviour theory, adolescents may exhibit multiple problem behaviours including substance abuse. ${ }^{1}$ To date, many intervention programmes are being delivered to address substance abuse disorder among young people. It is important that we examine both interactive and non-interactive programmes to see the deliverables and the implications to young people.

\section{Involvement of young people in the prevention of substance abuse: methods that work}

"Drug trafficking, once viewed largely as a social and criminal problem, has transformed in recent years into a major threat to the health and security of 
people and regions," observed the United Nations Secretary General, Ban Ki-moon in June 2011. ${ }^{2}$ Substance abuse has been increasing among the youth population, in spite of the huge investment in a wide range of activities to keep young people safe and healthy.

However, there have been small targeted interventions that allow the participation of young people and these appear to have a higher impact when delivered by the youth. While most substance abuse programmes rely more on non-interactive delivery interventions to help the youth, youth-led involvement in substance abuse prevention is more effective.

This article will examine substance abuse interactive peer-led youth interventions and discuss the positive aspects and the challenges such interventions poses to the participants. These measures are critical due to its impact on youth interventions; overall decline in substance abuse among the youth.

\section{Prevention programmes of substance use among youth}

In its resolution, "Measures to protect children and young people from drug abuse, the Commission on Narcotic Drugs (CND Resolution No. 53/10) encouraged member states to implement various interventions for the prevention of drug use and the protection of children", the resolution gave an insight into the need for measures to protect children and youth from drug abuse which appears to be increasing globally. Thus, comprehensive programmes widely recommended by the United Nations Commission on Narcotic Drugs $(\mathrm{E} / \mathrm{CN} / 7 / 2011)$ for the prevention of substance abuse include the following. ${ }^{3}$

- Dissemination of information about dangers of drug use.

- Education in schools based on life skills.

- Alternative activities (e.g. sports, drama, music.)

- Family and parenting skills training.

- Workplace programmes.

- Vocational training and income-generation support.

- Media campaigns.

- Screening and brief interventions.

UNODC) literature on drug abuse indicates that comprehensive programme interventions covering the general population are still reported more com- 
monly than implementation programmes for the youth. The United Nations Commission on Narcotics on Drugs (E/CN/7/2011) reported that only three out of eight such programmes targeted young people. ${ }^{3}$

Most countries reported poor coverage in terms of numbers reached and over concentration of programmes in schools. Many young people, especially in the developing world are out of school and as such these youth are generally left out. This shows that well-planned and targeted interventions for youth are still lacking. Substantial information about the delivery of youth interventions shows a mixed coverage, but this again may not mean good coverage of content either. ${ }^{4}$

\section{Content and methods of delivery of peer youth led programmes}

Non-interactive programmes that cover the general youth population have been found to be partially effective. Programme analysts argue that content is introduced by the teacher and delivered in an instructive manner to alter knowledge, attitudes and to value decision-making-based content for young people. These have been found to be ineffective. Moskowitz argues that:

"These programmes again fail to take into consideration and acknowledge the individual youth differences and experiences with regards to levels of risks of drug use and quite often assume the youth groups are homogeneous. The worry here is that in some instances such interventions may increase alcohol and other drug use". ${ }^{5}$

In spite of the good intentions of these interventions, the delivery of the non-interactive programmes faces several challenges. Teachers may at times be unaccountable in passing over some information or may assume the youth know it already. Black, et. al, observes that "non-interactive activities are teacher-to-student led, rather that youth-to-youth led. ${ }^{4}$

In these circumstances, lack of experience and passivity of youth participants is largely visible and many times, their input to the training sessions is minimal and sometimes student responses are directed towards what the teacher wants to hear". ${ }^{4}$ The delivery of non-youth led programmes is limited primarily to the modification of behaviour and habit change and less on how behaviour is initiated or how new habits develop.

DiClemente, has argued that:

"These prevention efforts would consist of targeting the behavioural 
construct associated with stages for modification, to affect the stage status of the youth across each of these stages". ${ }^{6}$

\section{The case for peer interactive youth-led programmes}

Interactive peer youth-led programmes require that beneficiaries of the messages for youths be part of the intervention in all aspects. The concept of peer-led substance abuse education provides a rationale and effective vehicle for using drug peer counsellors as a major strategy in community-based drug abuse prevention programmes. Youth-led activities are planned to effectively stimulate the active participation of all youth and fellow students who generate real role-play within their environments. Inter-personal skills are modeled, adapted and re-hashed here in addition to youth peer leaders giving feedback to supervisors from the peers. Black et al. have noted that:

"The peer-led prevention programmes were superior to teacher-led programmes and the control conditions in their effect on cigarette smoking, excessive drinking and use of cannabis. Significant changes were noted in select cognitive, attitudinal and personality predisposing variables. The lack of significant teacher results was maybe because teachers received no monitoring or assistance. Conversely, peers were trained in that they were provided with a series of pre-session briefings and their programmes were monitored by the research staff'. ${ }^{4}$

\section{Working with young people to prevent drugs - UYDEL project}

Following is a case study implemented by the Uganda Youth Development Link (UYDEL) initiatives which focuses on youth-led interactive activities.

"UYDEL is implementing a one-year project supported by UNODC and DPAC entitled: "Kampala young people's initiative towards drug abuse prevention in slum communities".

The goals of this project is to empower 40 young people to become the initiators of the drug abuse prevention programmes in their slum communities and to make young people appreciate and apply international standards on drug use prevention. This project has been looking at young people who can be empowered to prevent and disseminate information on drug abuse prevention.

The major purpose for the setting up of this peer-led project was basically due to the increased cases of drug use among the young people in most of Kampala slum communities. In order to ensure active and not just passive participation of the peers, most of the activities under this 
project are based on the concept of "Participatory Inquiry in Practice" where young people, being considered as knowledgeable of what really happens in their lives and that of the people in the same age group, are trained in the running of the prevention activities with minimal guidance from the assigned social workers and project coordinators.

To ensure active involvement, the peer-led prevention programme was started by identifying and screening young people who participated in the different centres of UYDEL. For instance Bwaise, Makindye, Kawmokya, Nakulabye, Nateete and one vocational rehabilitation centre in Masooli and 40 self-selected youth. The peers were trained in basic research methodology and ethics of collecting data. The exercise took a period of one week. It was brought to our attention that majority of the drug users in the Kampala slum communities are under the age group of 15-19 years. Peers wrote a report and have been disseminating findings in their communities.

The findings showed that the most common type of drugs accessed by these slum youths were marijuana and alcohol, accounting for $80 \%$. The research findings also revealed that CSOs are still reluctant in playing their role in order to secure a healthy and stronger generation free from drugs. Most of the slum youths who were interviewed acknowledged that there has been no intervention to prevent drug abuse apart from the role of the Police to maintain law and order. Following the research based intervention, peers under the project carried out six school outreaches; dramas and debates to interact with youths in their communities.

Following the international standards in 2011 of the UNODC, peers under the project participated in the UN Day celebrations on $26^{\text {th }}$ June 2014, on drug abuse and illicit trafficking. In their celebrations they reached out to over 600 young people with the theme "It's better not to start; because stopping is difficult" and this was all enclosed under the need to stop drug and substance use among the young people.

Peers were also equipped with different computer skills, especially so to help spread the news through mainly the social media which is key in knowledge management and sharing. They created their Face Book page which is not only used to post the project activities and experiences but also educate the young population about healthy living and making the right decisions. Among the posts: "Drugs makes you high but they deduct on the days you have on this earth" by Ntongo Dorothy, one of the peers of the initiative. Another one is "Stop drug abuse towards Africa" by Ssaka Charles, a peer under the prevention 
programme.

Young people are now knowledgeable and if equipped with the skills to fight the vice of drug abuse may extend the knowledge to others. Peers under the project use interactive activities which they find interesting since they use social skills to prevent drugs use among them and other young people. Among the lessons learned is that young people should be included whenever an intervention is to be made because they are the most knowledgeable about the problems affecting them. There is also a need for continuous sensitisation of the young people in the slum areas about the risks and adverse effects of abusing drugs. This should not be limited to health, but should include the social and economic effects associated with the vice.

As the case study above has shown, youth-led interactive activities have a high superiority rate due to the appropriate packaging of messages, timing and use of non-sophisticated examples and registered less drunkenness and alcohol use.

Peer-led discussions provide multiple channels of communication using slang and language common to their peers through interpersonal activities such as role play, drama and at the same time communicating within their environment thus enhancing the chances of influencing behaviour. The style of delivery of youth programmes needs to be participatory, promoting friendship, in a face-to-face manner, open and guarantees feedback that are not authoritarian and reprimanding as provided by the above UYDEL UNODC project. Interactive programmes normally provide peer instructions on the immediate negative effects of drug use and sometimes may constitute sanctions for its members who may deviate.

Additional activities identified by peers to integrate and disseminate information include sports and other recreational activities that are promoted and used as opportunities for young people to progress. Each one becomes 'the other's keeper', providing good role models that portray health-seeking behaviour, peer pressure, stress management and a step-by-step process on how to sustain the desired positive behaviour.

In comparison, we have been able to draw key characteristics that form the core of peer youth-led programmes as shown in table below: 
Table 1. Key characteristics of interactive peer youth-led activities

\begin{tabular}{l}
\hline Adapting to local environments as peer counsellors deliver sessions on time \\
\hline $\begin{array}{l}\text { Participatory in nature: stimulate sessions led by the youth as participation gen- } \\
\text { erates trust }\end{array}$ \\
\hline Provides positive role models and consistent messages when needed \\
\hline $\begin{array}{l}\text { Real case situations are developed, sensitive to the youth's stages of develop- } \\
\text { ment and matched interventions }\end{array}$ \\
\hline $\begin{array}{l}\text { Provides useful multiple feedback to the youth and facilitators and allows } \\
\text { change }\end{array}$ \\
\hline $\begin{array}{l}\text { Promotes use of local languages and content delivered by the youth in the con- } \\
\text { text of age, experience and environment }\end{array}$ \\
\hline Provides opportunity for timely intervention by peer leaders when needed \\
\hline Promotes use of appropriate messages interwoven with life skills \\
\hline $\begin{array}{l}\text { Generates real answers and appreciates individual differences and experiences } \\
\text { with regard to risks }\end{array}$ \\
\hline Non-judgmental and without apportion blame and reduce labeling \\
\hline Covers a large youth population and requires less resources \\
\hline Young people develop leadership skills and advocacy \\
\hline Allows youth to make an input in the session and minimises passivity \\
\hline
\end{tabular}

Note: This table was created on information from articles on substance abuse prevention by National Institute of Drug abuse (NIDA) ${ }^{4,6}$

\section{Implications}

In the foregoing paragraphs, it is important to highlight that for peer-led programmes to be effective, they must provide comprehensive training, give accurate information on behavioural skills and be carefully planned to match prevention activities to the needs; age, gender and types of drugs that the youth uses. ${ }^{7}$ Prevention efforts are likely to succeed, if peer educators are well prepared and if they are accurately matched to specific development stage of each adolescent and the type of substance they use. ${ }^{8}$ Screening and selecting of peers must look out for peers who are helpful, trustworthy, caring, good listeners and positive role models. However, in spite of the good intentions of peer-led programmes, the youth may fail to express themselves well and may have inadequate information, therefore needing regular training in order to minimise the adverse effects. ${ }^{8,9}$ 


\section{Conclusion}

Peer-led programmes are fewer globally and may take time to expand. However, they are inclusive and have been found to have a higher efficacy and interactive levels. Youth-led interactive programmes have a high superiority rate and significantly register less drunkenness and lower alcohol use among the peer-led groups. These peer led programmes require careful planning, training, screening and refocus on substance abuse. In addition, screening and selecting peers look out for those who are helpful, trustworthy, caring and those who are good listeners.

These programmes need to be supported, monitored and at times supplemented by other intervention models including multiple delivery involving parents and other livelihood needs. So as not to under-rate or over-emphasise and assume that all adolescents are homogeneous and deserve the same menu.

\section{References}

1. Jessor R, Jessor S. Problem behaviour and psychological development. New York Academic Press. 1977.

2. United Nations Secretary General, Kim Moon, June 2011 Speech to the United Nations Day against Drug Abuse, www.unodc.org

3. United Nation report; Commission on Narcotic Drug Fifty Fourth Session, Vienna, 21-25 March 2011, United Nations Economic and Social Council, E/CN.7/2011/13.

4. Black DR, Nancy S, Tobler J, Sciacca S, Peer helping or involvement. An efficacious way to meet the challenges of reducing alcohol, tobacco, and other drugs among youth. Journal of School Health. 1998 Mar;68(3):87.

5. Moskowitz JM. The primary prevention of alcohol problems: A Critical Review of Research Literature. Journal of Studies on Alcohol, 1989;50:54-88.

Doi: http://dx.doi.org/10.15288/jsa.1989.50.54

6. Diclemente C, Proscka JO, Fairhurst SK, Velicer WF, Fairhurst SK, Rossi JS. The processes of Smoking Cessation: An analysis of Pre-contemplation, contemplation and preparation in stages of Change. Journal of Consulting and Clinical Psychology, 1998;59;295-304.

Doi: http://dx.doi.org/10.1037/0022-006X.59.2.295 
7. Botvin GJ, Baker E, Dusenbury L, Botvin EM, Diaz T. Long Term Follow-up Results of Randomized Drug Abuse Prevention Trial in a White Middle-class Population; JAMA, 1995;273(14):1106-12 Doi: http://dx.doi.org/10.1001/jama.1995.03520380042033

8. Chudley E, Werch H, DiClemente C. A multi-component stage model for matching drug prevention strategies and messages to the youth stages of use. Health Education Research; Theory and practice. 1994;9:37-46.

9. Perry CL, Grant M. Comparing peer-led to teach-led Youth Alcohol Education in Four Countries, Alcohol Health Res World 1988;12:32226. 